\title{
Die Nomenklatur der revidierten Tarifstruktur ist bereit!
}

\author{
Dr. med. Urs Stoffel
}

Mitglied des FMH-Zentralvorstandes, Departementsverantwortlicher Ambulante Versorgung und Tarife

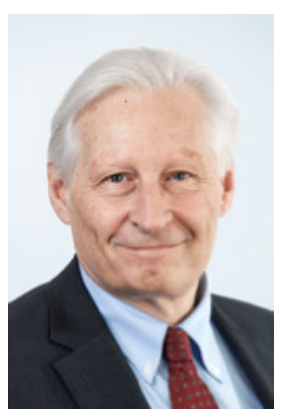

Das Fundament eines Einzelleistungstarifs ist die Nomenklatur. Unabhängig davon, ob nun Einzelleistungen tarifiert oder einzelne Pauschalen für gut abgrenzbare Leistungen ausgehandelt werden, ist sie das Herzstück eines sachgerechten und betriebswirtschaftlich berechneten Tarifs. Ohne diese ausgewogene, in sich geschlossene und innerhalb der einzelnen Tarifpositionen abgestimmte Leistungsstruktur ist ein sachgerechter und ausgewogener Tarif zur Abgeltung der ärztlichen Leistungen nicht möglich.

Diese Nomenklatur liegt nun vor und wurde am 11. April 2018 an der ausserordentlichen Delegiertenversammlung der FMH einstimmig verabschiedet. Zuvor war sie bereits vom COCKPIT, dem aus allen Dachorganisationen zusammengesetzten ProjektSteuerungsorgan, genehmigt worden. Das ist ein starkes Zeichen für die weiteren Verhandlungen der Tarifstruktur mit den Tarifpartnern. Der Entscheid der Delegiertenversammlung soll nun im Mai 2018 der Ärztekammer zur Genehmigung vorgelegt werden.

Eine kohärente und gut abgestimmte Nomenklatur ist das Herzstück eines sachgerechten und ausgewogenen Tarifs.

Nach wie vor ist die gesetzliche Vorgabe, welche eine sachgerechte und nach betriebswirtschaftlichen Kriterien berechnete Tarifstruktur fordert (Art. 43, Abs. 4 KVG), für die FMH verbindlich. Dies auch wenn der jüngste Bundesgerichtsentscheid zum ersten Tarifeingriff des Bundesrates von 2014 die Sachgerechtigkeit und betriebswirtschaftliche Bemessung der Tarifstruktur zu Gunsten politischer Ziele in Frage stellt. Selbstverständlich müssen zur Erreichung des Ziels einer gemeinsamen, tarifpartnerschaftlichen Tarifstruktur auch die Anliegen der Tarifpartner berücksichtigt werden und in die Verhandlungen einfliessen. Das Ziel kann nur dann erreicht werden, wenn ALLE Tarifpartner bereit sind, bei diesen Verhandlungen Kompromisse einzugehen. Um gemeinsam einen sachgerechten Tarif zu erarbeiten und laufend weiterzuentwickeln, haben sich die vier Tarifpartner FMH, $\mathrm{H}+$, curafutura und MTK im Januar 2016 in der Gemein- schaft ats-tms AG zusammengeschlossen. Die Verhandlungen mit diesen Tarifpartnern zur Integration des TARCO in eine gemeinsame Tarifstruktur laufen zurzeit auf Hochtouren.

Wie geht es nun weiter, und was sind die kommenden Etappenziele? Parallel zu den laufenden Verhandlungen mit den Tarifpartnern sollen die Kostenmodelle für die Arztpraxen und Spitäler aktualisiert werden und die einzelnen Tarifpositionen mit den entsprechenden Taxpunkten hinterlegt werden. Nachdem diese Arbeiten abgeschlossen sind, ist für Ende Mai 2018 die Genehmigung der Kostenmodelle mit den

\section{Die Nomenklatur wurde an der ausser-}

\section{ordentlichen Delegiertenversammlung der}

FMH einstimmig verabschiedet.

Taxpunkten durch das Steuerungsorgan COCKPIT vorgesehen. Ende Juni 2018 soll dann die Delegiertenversammlung auf Antrag des COCKPITS die Leistungsstruktur TARCO mit den Kostenmodellen und den hinterlegten Taxpunkten genehmigen.

Gemäss Zeitplan der Gemeinschaft ats-tms AG, dem alle Tarifpartner zugestimmt haben, sollten diese Verhandlungen bis Mitte August 2018 abgeschlossen sein. Bei Differenzen oder Dissens werden selbstverständlich die zuständigen Fachgesellschaften laufend in die Verhandlungen eingebunden.

Im September 2018 wird dann die gesamte, mit den Tarifpartnern verhandelte Endfassung der Tarifstruktur mit dem dazugehörigen Regelwerk und dem Rahmenvertrag der Delegiertenversammlung zur Genehmigung vorgelegt werden. Schliesslich soll im Oktober 2018 die definitive Tarifstruktur auch von der Ärztekammer verabschiedet werden. Parallel dazu werden auch die Tarifpartner die abgeschlossene und gemeinsam erarbeitete Tarifstruktur ihren Organen zur Genehmigung vorlegen. Es ist unser erklärtes Ziel zur Wiederherstellung der Tarifpartnerschaft, dem Bundesrat Ende 2018 eine revidierte und gemeinsam erarbeitete, gesetzeskonforme ambulante Tarifstruktur zur Genehmigung einzureichen. Lesen Sie mehr zum Projekt TARCO im Artikel von Christian Oeschger auf Seite 536. 